\title{
$n$-Pentane isomerization over promoted SZ/MCM-41 catalysts
}

\author{
Wei Wang ${ }^{\mathrm{a}}$, Jung-Hui Wang ${ }^{\mathrm{b}}$, Chang-Lin Chen ${ }^{\mathrm{a}}$, \\ Nan-Ping $\mathrm{Xu}^{\mathrm{a}}$, Chung-Yuan $\mathrm{Mou}^{\mathrm{b}, *}$ \\ ${ }^{a}$ College of Chemistry and Chemical Engineering, Nanjing University of Technology, \\ Nanjing 210009, China \\ ${ }^{\mathrm{b}}$ Department of Chemistry, National Taiwan University, 1 Roosevelt Road, \\ Section 4, Taipei 106, Taiwan \\ Available online 11 September 2004
}

\begin{abstract}
With metal sulfate as the precursor, the catalysts of sulfated zirconia on MCM-41, Al- and Ga-promoted sulfated zirconia on MCM-41 (named as SZ/MCM-41, ASZ/MCM-41 and GSZ/MCM-41, respectively) were prepared by direct dispersion in the as-synthesized MCM-41 materials, followed by thermal decomposition. The catalysts were characterized with various techniques such as XRD, FTIR, $\mathrm{N}_{2}$ adsorption, $\mathrm{NH}_{3}$-TPD, DRIFT, and TPR-MS. The ordered porous structure was still maintained in the catalysts. The addition of promoters helps to retard the phase transformation of $\mathrm{ZrO}_{2}$ from tetragonal phase to monoclinic phase. Isomerization of $n$-pentane was investigated over the catalysts. In comparison to SZ/MCM-41, both promoted catalysts showed much improved catalytic activity and selectivity for isomerization of $n$ pentane. Moreover, the catalytical activities of both promoted catalysts for pentane isomerization remained steady over the period of 180 min while the activities of the unpromoted catalyst decreased in $<120 \mathrm{~min}$. Characterization of acidity showed no significant difference in strength distributions of the acid sites over the catalysts. The nature of acid sites in SZ/MCM-41 was affected by the presence of aluminum, but not affected by the presence of gallium. On the other hand, TPR study shows sulfur on GSZ/MCM-41 is much easier to reduce than SZ/MCM-41 and ASZ/MCM-41. The presence of gallium improved the redox capability provided by the sulfate ions in GSZ/MCM-41 catalyst. The causes for the promotion effects of $\mathrm{Ga}$ and $\mathrm{Al}$ are discussed.
\end{abstract}

(C) 2004 Elsevier B.V. All rights reserved.

Keywords: Mesoporous; Sulfated zirconia; Promoter; Isomerization; $n$-pentane

\section{Introduction}

The trend of existing and forthcoming regulations on gasoline has highlighted the need for "clean" high-octane molecules in the gasoline pool. To increase the octane number of the gasoline pool, the light straight run (LSR) gasoline fraction of oil need to be isomerized and in this way its research octane number (RON) increases from $\sim 64$ to $\sim 80$. This increase is achieved by isomerizing $n$-pentane and $n$-hexane, which are the main components of LSR. Isomerization of $n$-pentane and $n$-hexane has the right combination of RON/MON properties and compliance with environmental regulations. The commercial catalysts used for carrying out this isomerization are $\mathrm{Pt}$ on chlorinated

\footnotetext{
* Corresponding author. Fax: +88622366954.

E-mail address: cymou@ntu.edu.tw (C.-Y. Mou).
}

alumina and $\mathrm{Pt} / \mathrm{H}$-mordenite. However, a major drawback of the former is the sensitivity to water and sulfur even in concentrations as low as $10 \mathrm{ppm}$. On the other hand, the latter requires higher reaction temperature $\left(250{ }^{\circ} \mathrm{C}\right)$ with the corresponding 2-point RON penalty. The environmental problems with the regeneration of these catalysts have also revived interest in halogen-free isomerization catalysts.

Solid acid catalysts are required for the isomerizations of alkanes and a renewed interest in their use is noticeable in the last few years. Among them, sulfated zirconia is attractive since it offers a nice alternative to the corrosive halogen-containing solid acids in the skeletal isomerization of light linear alkanes at low temperature. Much work has been devoted to sulfated zirconia and discussed in several reviews [1-7]. These catalysts exhibit high initial activity that may decline rapidly unless certain metals are present. In 
fact, incorporation of Pt leads to a SZ catalyst that retains its activity for a much longer period of operation than the metal-free SZ [8-13]. In the case of $n$-pentane isomerization, the de-activation was more severe if no $\mathrm{Pt}$ metal is added to the catalyst. However, even with platinum insertion the catalytic activity is still relatively low. Similarly, some transition metals, such as Fe, Mn [14-17], incorporations have been reported capable of enhancing $n$-alkane conversion activity. However, after an induction period during which a maximum activity is obtained, the performance of these metal-promoted SZ catalysts tends to decline with time also [18].

An important factor affecting the performance of the solid acid catalyst is its texture porosity. Typically, surface areas for active SZ is about $100 \mathrm{~m}^{2} / \mathrm{g}$ in the tetragonal crystalline phase. However, recently Risch and Wolf reported mesoporous sulfated zirconia catalyst with surface area $269 \mathrm{~m}^{2} / \mathrm{g}$ and obtained significantly higher activity for isomerization of butane and pentane [19]. Therefore, it is desirable to design a sulfated zirconia catalyst system with both mesoporosity and metal promoter simultaneously to gain both high activity and stability. Several papers have been published on the preparation and applications of SZ supported on various mesoporous silica [20-23].

Recently, we have reported elsewhere that the addition of small amounts of main group metals, such as $\mathrm{Al}[24,25]$ and $\mathrm{Ga}[26]$ to the sulfated zirconia on mesoporous MCM-41 gives rise to the catalysts much more active than the corresponding unpromoted sulfated zirconia on MCM-41 for $n$-butane isomerization at $250{ }^{\circ} \mathrm{C}$ in the presence of $\mathrm{H}_{2}$. The results suggest that the same catalysts might be useful for isomerization of other light alkanes. In the present work, isomerization of $n$-pentane was investigated over SZ/MCM41, ASZ/MCM-41, and GSZ/MCM-41 catalysts. The activities of promoted catalysts for $n$-pentane isomerization with changing reaction temperature were studied. Addition of $\mathrm{Al}$ and $\mathrm{Ga}$ prevented the rapid deactivation of the catalyst. The catalysts were characterized by XRD, FTIR, $\mathrm{N}_{2}$ adsorption, $\mathrm{NH}_{3}$-TPD, DRIFT, and TPR-MS. The reasons for the improvement on activity and stability of the catalysts in $n$-pentane isomerization by the addition of promoters are discussed.

\section{Experimental}

\subsection{Catalysts preparation}

As-synthesized pure siliceous MCM-41 was synthesized with the delayed neutralization process [27]. The assynthesized mesoporous material was impregnated with a desired amount of $\mathrm{Zr}\left(\mathrm{SO}_{4}\right)_{2}$ in methanol and stirred for $15 \mathrm{~h}$ at room temperature. The resulting sample was dried at $80{ }^{\circ} \mathrm{C}$. Finally, it was calcined at $660{ }^{\circ} \mathrm{C}$ for $3 \mathrm{~h}$ in air. Gaand $\mathrm{Al}$-promoted samples were prepared in the same way with the desired amount of zirconium sulfate and gallium sulfate or aluminum sulfate mixture. $\mathrm{ZrO}_{2}$ content was kept at $50 \mathrm{wt} . \%$ on each sample.

\subsection{Catalysts characterization}

XRD patterns of the samples were obtained on a Bruker D8 Advance instrument with $\mathrm{Cu} \mathrm{K} \alpha$ radiation at $40 \mathrm{kV}$ and $30 \mathrm{~mA}$. FTIR absorption spectra were recorded on a Nicolet 550 spectrometer using a $\mathrm{KBr}$ pellet. About $1 \mathrm{mg}$ of sample was mixed with $300 \mathrm{mg}$ of dried $\mathrm{KBr}$ and then pressed. The surface area and pore size distribution measurements were carried out on a Micromeritics ASAP 2010 automatic adsorption instrument using $\mathrm{N}_{2}$ gas. Sulfur content in the catalysts was detected by a chemical method. The sulfate was turned into $\mathrm{BaSO}_{4}$ and determined by gravimetric method. The TPR and $\mathrm{NH}_{3}$-TPD were carried out on a Micromeritics AutoChem 2910 instrument. In $\mathrm{NH}_{3}$-TPD experiment, about $100 \mathrm{mg}$ of dried sample was pre-treated at $500{ }^{\circ} \mathrm{C}$ under ultra-high pure helium $(50 \mathrm{ml} /$ $\min$ ) for $1 \mathrm{~h}$ and then cooled to $120^{\circ} \mathrm{C}$. After introducing $3 \% \mathrm{NH}_{3}$ in $\mathrm{He}$ at $120{ }^{\circ} \mathrm{C}$ for $0.5 \mathrm{~h}$, the sample was flushed with helium for $1.5 \mathrm{~h}$. The TPD profile of ammonia was obtained from 120 to $720{ }^{\circ} \mathrm{C}$ at a heating rate of $10{ }^{\circ} \mathrm{C} / \mathrm{min}$. In TPR experiment, about $80 \mathrm{mg}$ of dried sample was pretreated at $500{ }^{\circ} \mathrm{C}$ under air $(40 \mathrm{ml} / \mathrm{min})$ for $1 \mathrm{~h}$ and then cooled to $120{ }^{\circ} \mathrm{C}$. The TPR profile was recorded in $10 \% \mathrm{H}_{2} /$ Ar of $40 \mathrm{ml} / \mathrm{min}$ from 120 to $800{ }^{\circ} \mathrm{C}$ at $15^{\circ} \mathrm{C} / \mathrm{min}$. The desorption process was monitored by a Quadruple Mass Spectrometer (Thermo ONIX, ProLab) connected on-line through a heated capillary interface. Diffuse reflectance infrared Fourier transform (DRIFT) spectra of the samples were recorded using a BOMEM MB155 FT-IR/Raman spectrometer. The equipment was furnished with an in situ sample cell (Harrick). The sample was pre-heated at $300{ }^{\circ} \mathrm{C}$ for $3 \mathrm{~h}$ under $10^{-6}$ mbar vacuum before pyridine vapor was introduced at room temperature, followed by evacuation for $1 \mathrm{~h}$.

\subsection{Catalytic tests}

The isomerization of $n$-pentane was performed in a fixedbed continuous flow reactor. The catalyst samples were palletized and sized to 20/60 mesh. Approximately $0.7 \mathrm{~g}$ of the catalyst was loaded into the steel reactor and then pretreated at $450{ }^{\circ} \mathrm{C}$ in flowing dry air $(20 \mathrm{ml} / \mathrm{min})$ for $3 \mathrm{~h}$ at atmospheric pressure. The reactor temperature was then lowered to the desired reaction temperature, mostly $180{ }^{\circ} \mathrm{C}$ or other desired temperature. After thermal equilibrium was established, the unit was pressurized with hydrogen to 2.0 MPa. $n$-Pentane was fed into the reactor using a highpressure pump. Hydrogen and $n$-pentane flow rates were adjusted to give a $5 \mathrm{H}_{2} / n$-C5 mole ratio. The $n$-pentane weight hourly space velocity (WHSV) is $3.0 \mathrm{~h}^{-1}$. An on-line gas chromatograph equipped with FID was used to analyze the reaction products. 


\section{Results}

\subsection{Crystalline structure of catalysts}

Fig. 1 shows the powder XRD patterns of the SZ/MCM41 and the promoted catalysts. As can be seen, all samples show a diffraction peak due to the $\left(\begin{array}{lll}1 & 0 & 0\end{array}\right)$ reflection of MCM-41 at low $2 \theta$ ranges, which is usually used to characterize the ordered porous structure. The XRD results show that the structure of the mesoporous molecular sieve is still well-maintained after the loading of the catalyst. Fig. 1 also gives very weak and broad reflections in the higher $2 \theta$ range (above $30^{\circ}$ ). This suggests that very small sulfated zirconia particles were formed. When the XRD patterns at higher ranges are magnified ten times, it can be seen that a small amount of monoclinic $\mathrm{ZrO}_{2}$ phase, which is less active than tetragonal $\mathrm{ZrO} 2$ phase, is presented in SZ/MCM-41 along with the tetragonal $\mathrm{ZrO}_{2}$ phase. For the promoted catalysts only the tetragonal phase can be observed. It is reported that the dispersion threshold of zirconium sulfate is ca. $0.26 \mathrm{~g} / 100 \mathrm{~m}^{2}$ on silica [28]. Monoclinic $\mathrm{ZrO}_{2}$ phase was observed when the $\mathrm{Zr}\left(\mathrm{SO}_{4}\right)_{2}$ loading was above the dispersion threshold. In our experiment, zirconium sulfate content was kept at $0.268 \mathrm{~g} / 100 \mathrm{~m}^{2}$ on each support, which is slightly above the dispersion threshold of zirconium sulfate on MCM41. These results indicate that the transformation from the metastable tetragonal phase to the monoclinic phase is retarded in the presence of promoters.

To confirm further the retardation of the phase transformation of $\mathrm{ZrO}_{2}$ from tetragonal phase to monoclinic phase for the promoted catalysts, a systematic study using IR technique was undertaken. The MCM-41 calcined at $660{ }^{\circ} \mathrm{C}$ was used for comparison. Fig. 2 shows the FTIR spectrum of the catalysts. The spectrum of SZ/MCM-41 presents one band due to $\mathrm{Zr}-\mathrm{O}$ bond vibrations. It is situated at $750 \mathrm{~cm}^{-1}$ and assigned to $\mathrm{m}-\mathrm{ZrO} 2$ [29]. However, it disappeared with the addition of promoters. It indicates that the tetragonal

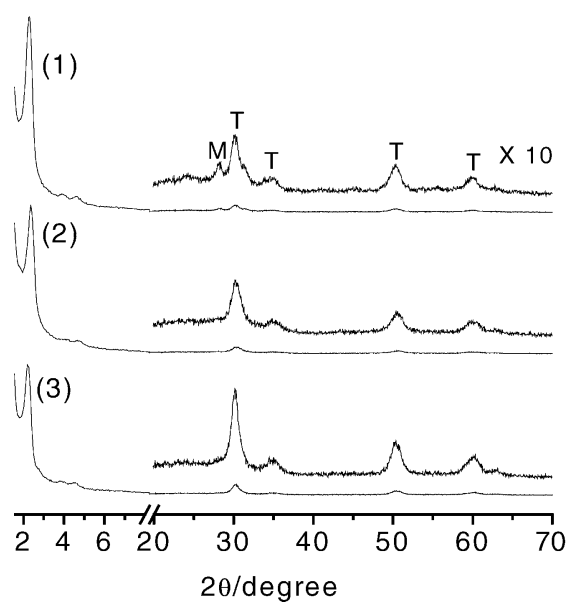

Fig. 1. X-ray diffraction patterns of the catalysts calcined at $660{ }^{\circ} \mathrm{C}$. (1) SZ/ MCM-41, (2) ASZ/MCM-41, (3) GSZ/MCM-41. T, tetragonal phase; M, monoclinic phase.

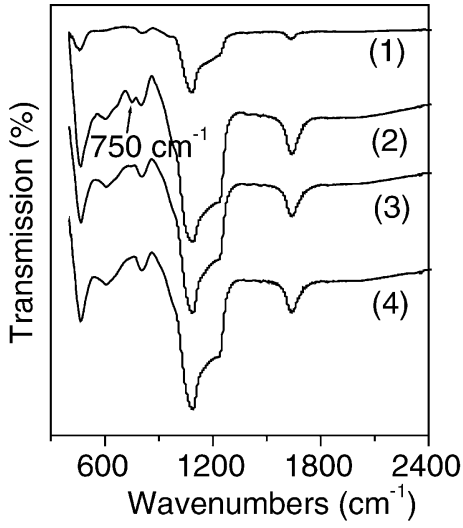

Fig. 2. FTIR spectra of (1) MCM-41, (2) SZ/MCM-41, (3) ASZ/MCM-41, (4) GSZ/MCM-41.

phase of $\mathrm{ZrO}_{2}$ may have been stabilized by the addition of promoters.

\subsection{Physico-chemical properties of samples}

The $\mathrm{N}_{2}$ adsorption/desorption isotherms were measured and pore size distributions of SZ/MCM-41 were calculated. These samples show type IV isotherms as they are expected for mesoporous systems. Table 1 shows the sulfur content, BET surface area, pore volume, and pore diameter of the catalysts. Data of the parent MCM-41 carrier is also given in Table 1 for comparison. The surface areas of samples were decreased with the deposition of sulfated zirconia modified samples in comparison to that of parent MCM-41, and the pore volume values were also decreased at the same time. The pore diameter of SZ/MCM-41 is less than that of the siliceous MCM-41 support. These results indicate that the supported sulfated zirconia has been well-dispersed into the mesopores of MCM-41. However, the surface area of the catalysts is still over $300 \mathrm{~m}^{2} / \mathrm{g}$, which is larger than that of the traditional sulfated zirconia, typically below $100 \mathrm{~m}^{2} / \mathrm{g}$ [30]. The sulfur content increases with the incorporation of promoter. There is a very small difference between ASZ/ MCM-41 and GSZ/MCM-41 catalysts as far as its effect on sulfur loading is concerned. It may be explained that promotion with $\mathrm{Ga}$ and $\mathrm{Al}$ had a favorable effect on sulfate retention with respect to SZ/MCM-41 catalyst during calcinations of the catalysts.

\subsection{Surface acidity studies of the catalysts}

Two methods were used to characterize the acidic properties of the samples: the $\mathrm{NH}_{3}$-TPD was used to characterize the acid strength distribution of the catalysts. DRIFT spectroscopy was carried out in order to distinguish between Lewis and Brønsted acid sites.

The $\mathrm{NH}_{3}$-TPD spectra of the catalysts are shown in Fig. 3. These catalysts are characterized by similar broad desorption patterns peaked at $215^{\circ} \mathrm{C}$, spanning in the range 
Table 1

Physico-chemical properties of the supported catalysts and the support

\begin{tabular}{lllll}
\hline Sample & $\begin{array}{l}\text { Sulfur } \\
\text { content } \\
(w t . \%)\end{array}$ & $\begin{array}{l}\text { BET } \\
\text { S.A. } \\
\left(\mathrm{m}^{2} / \mathrm{g}\right)\end{array}$ & $\begin{array}{l}\text { Pore } \\
\text { volume } \\
\left(\mathrm{cm}^{3} / \mathrm{g}\right)\end{array}$ & $\begin{array}{l}\text { Pore } \\
\text { diameter } \\
(\mathrm{nm})\end{array}$ \\
\hline SZ/MCM-41 & 1.01 & 407 & 0.262 & 2.17 \\
ASZ/MCM-41 & 1.45 & 320 & 0.239 & 2.07 \\
GSZ/MCM-41 & 1.46 & 318 & 0.231 & 2.17 \\
MCM-41 & - & 857 & 0.703 & 2.33 \\
\hline
\end{tabular}

$150-550{ }^{\circ} \mathrm{C}$ and asymmetric on the high temperature side. This feature suggests the presence of sites with wide range of different acid strength. It is also found that there is no significant overall difference in the strength of acid sites with the addition of the promoters.

Fig. 4 shows the DRIFT spectra of the pyridine adsorbed samples at different temperature. Inspection of the spectra clearly shows that both Brønsted acid sites and Lewis acid sites are present on ASZ/MCM-41. When the promoter $\mathrm{Al}_{2} \mathrm{O}_{3}$ was introduced, the band at $1540 \mathrm{~cm}^{-1}$ corresponding to pyridine adsorbed on Brønsted acid sites appeared. However, the infrared spectra of both GSZ/MCM-41 and SZ/MCM-41 show that Lewis acid sites were dominant. The peak at $1540 \mathrm{~cm}^{-1}$ was not observed. Clearly, the nature of acid sites presents on SZ/MCM-41 is affected by the presence of aluminum, but not affected by the presence of gallium.

\subsection{Temperature-programmed reduction (TPR) analysis of the catalysts}

TPR profiles of the catalysts were measured in the temperature range $120-800{ }^{\circ} \mathrm{C}$. Here the gallium-promoted SZ/MCM-41 becomes the odd one. The TPR patterns for SZ/MCM-41 and ASZ/MCM-41 look very similar. There is only one large peak, starting near $570{ }^{\circ} \mathrm{C}$ and reaching maximum at $650-670{ }^{\circ} \mathrm{C}$. These results indicated that there was no difference of sulfate reduction with the addition of Al. However, the reduction of GSZ/MCM-41 occurs at

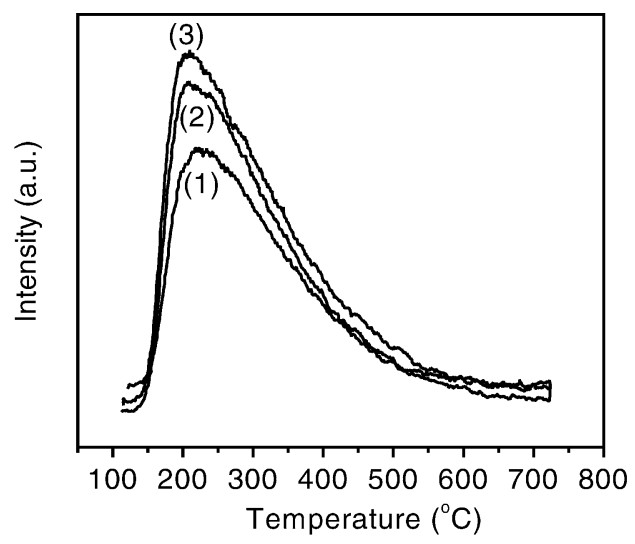

Fig. 3. $\mathrm{NH}_{3}$-TPD curves obtained on (1) SZ/MCM-41, (2) ASZ/MCM-41, (3) GSZ/MCM-41. temperatures much lower than that of SZ/MCM-41; the onset temperature for sulfate reduction in GSZ/MCM-41 is between 400 and $420{ }^{\circ} \mathrm{C}$. These results showed an enhancement of sulfate reduction by $\mathrm{Ga}$. On-line mass spectrometric analysis during the TPR runs with the catalysts confirmed the identity of the reduction products in the gas phase. Fig. 5 shows that $\mathrm{H}_{2} \mathrm{~S}$ is the only product (Fig. 5a), except water. And the $\mathrm{H}_{2}$ consumption curves (Fig. 5b) match that of $\mathrm{H}_{2} \mathrm{~S}$ evolution. The reduction profile of GSZ/MCM-41 exhibits a shift of the hydrogen consumption peak of about $120{ }^{\circ} \mathrm{C}$ towards lower temperatures, compared to the SZ/MCM-41 catalyst. The temperature for maximum hydrogen uptake of ASZ/MCM-41 is similar to that for SZ/MCM-41 catalyst. The addition of Al does not produce a significant effect over sulfate temperature reduction.

\subsection{Activity in n-pentane isomerization}

In the presence of the three catalysts, the predominant product was isopentane, formed with small amounts of methane, ethane, propane, butane, and isobutane. The conversion-time curves and selectivity-time curves obtained at $180{ }^{\circ} \mathrm{C}$ over the catalysts are compared in Fig. 6. Initial conversion obtained on SZ/MCM-41 is about $40 \%$ but then the catalyst quickly deactivate to a much lower conversion with time on stream. Both the promoted catalysts exhibited higher conversions and stability than SZ/MCM41. The GSZ/MCM-41 catalyst deactivates more slowly than the ASZ/MCM-41 catalyst. The initial conversion of the promoted catalysts is similar. In the $n$-butane isomerization reaction, the Al-promoted catalyst is appreciably less active than the Ga-promoted catalyst [26]. Here for pentane isomerization, the steady-state conversion of GSZ/MCM-41 at $77 \%$ is just slightly higher than that of ASZ/MCM- 41 . The steady-time selectivity to isopentane of the promoted catalysts is about $95 \%$. In the case of GSZ/MCM-41, the selectivity to isopentane remains constant with time on stream for the duration of the $180 \mathrm{~min}$ test and level off

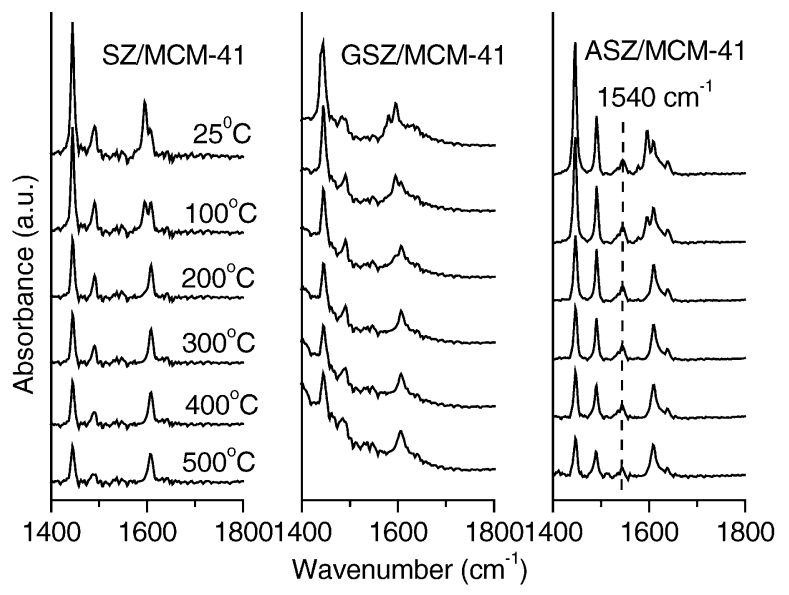

Fig. 4. DRIFT spectra of samples after adsorption of pyridine and evacuation at different temperature. 


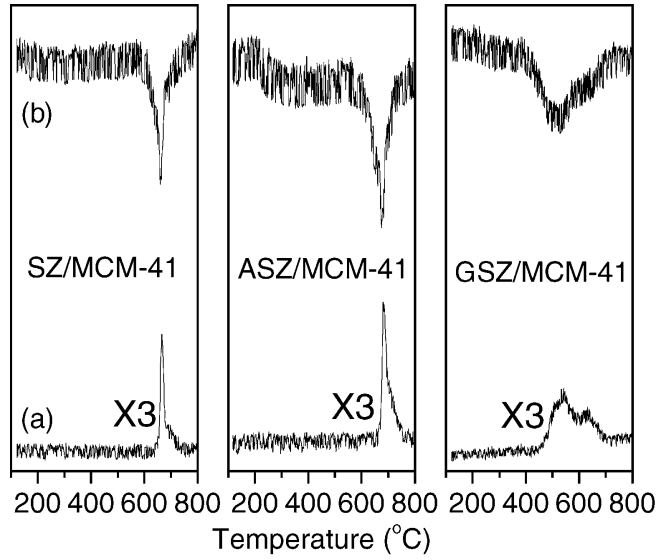

Fig. 5. Mass spectrometric detection of hydrogen consumption and evolution of $\mathrm{H}_{2} \mathrm{~S}$ during TPR of the catalysts: (a) $\mathrm{H}_{2} \mathrm{~S}$ evolution, (b) $\mathrm{H}_{2}$ consumption.

at approximately $95 \%$. In the case of ASZ/MCM-41, the initial selectivity is lower than that of GSZ/MCM-41.

There are a few recent reports on the isomerization of pentane by promoted sulfated zirconia [19,30]. Without promoters, the catalytic activity always decays rapidly with time. With Pt addition, the rapid initial deactivation is not detected but the initial activity is lower [19]. In Occelli work, copper was used as promoter with sulfated zirconia, the initial conversion at $15 \mathrm{~min}$ and $150{ }^{\circ} \mathrm{C}$ is about $53 \%$. But, they did not report on the stability of the catalyst. The catalytic activities and selectivity towards isopentane in our Al- and Ga-promoted catalysts appears to be very high.

The effect of reaction temperature on the promoted catalysts was investigated. The variation of the conversion and the corresponding selectivities at 20 and $180 \mathrm{~min}$ for Aland Ga-promoted SZ/MCM-41 catalysts are given in Fig. 7A and B. For the Ga-promoted catalyst, when the reaction temperature is increased to $180{ }^{\circ} \mathrm{C}$, it is observed that higher reaction temperature gave higher initial activity though the selectivity slightly decreases. The initial and steady-time selectivity at reaction temperature of $180{ }^{\circ} \mathrm{C}$ is above $94 \%$.
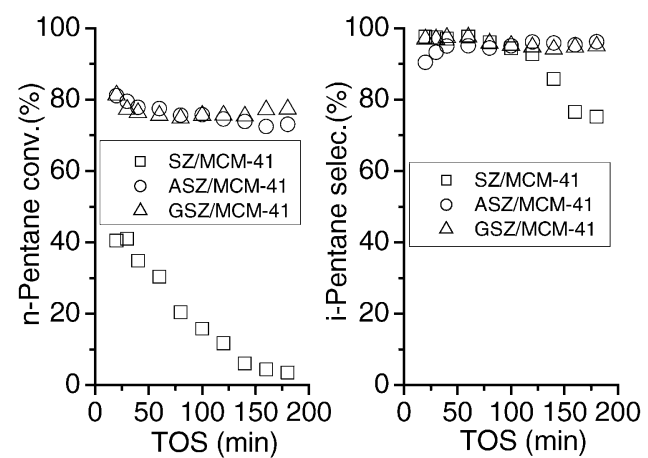

Fig. 6. Conversion of $n$-pentane and selectivity to isopentane vs. time on stream on SZ/MCM-41, ASZ/MCM-41, and GSZ/MCM-41 catalysts at $180{ }^{\circ} \mathrm{C}$.
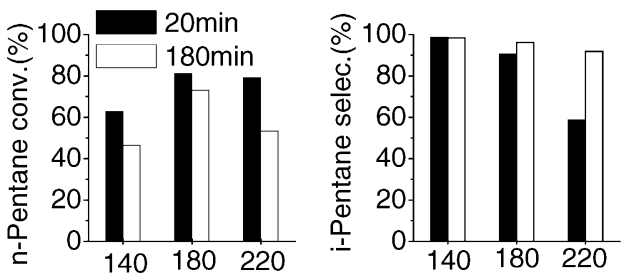

(A)
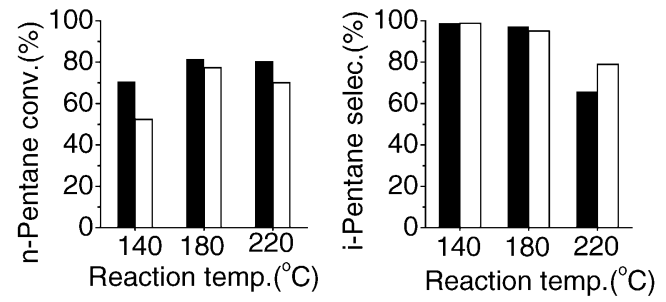

(B)

Fig. 7. Effect of reaction temperature on the conversion of $n$-pentane and selectivity to isopentane after 20 min reaction and at steady regime over ASZ/MCM-41 (A) and GSZ/MCM-41 (B), respectively.

When the reaction temperature is increased to $220^{\circ} \mathrm{C}$, the initial conversion at reaction temperature of $220^{\circ} \mathrm{C}$ is equal to that of $180^{\circ} \mathrm{C}$, however, the initial selectivity at reaction temperature of $220{ }^{\circ} \mathrm{C}$ decreases to about $60 \%$. For the $\mathrm{Al}-$ promoted catalyst, the $n$-pentane conversion is similar to that of GSZ/MCM-41. When the reaction was run at or below $180{ }^{\circ} \mathrm{C}$, isopentane was a major product. When the reaction temperature is increased to $220^{\circ} \mathrm{C}$, the initial selectivity decreases to about $60 \%$.

\section{Discussions}

We have investigated the promotion effects of main group metals $\mathrm{Al}$ and $\mathrm{Ga}$ on SZ/MCM-41 catalyst on the isomerization of pentane. The presence of promoters on SZ/MCM-41 is important to achieve good activity and stability during $n$-pentane isomerization. The rapid initial deactivation is not detected on the promoted catalysts. The $n$-pentane conversion over the two promoted catalysts is similar and the differences appear only slight after $120 \mathrm{~min}$. The selectivity towards isopentane is very high $(>95 \%)$ in all promoted catalysts, and it decays somewhat for the unpromoted SZ/MCM-41. In this section we discuss the possible causes of the promoting effect of $\mathrm{Al}$ and $\mathrm{Ga}$. The role of the promoters in the presence of hydrogen is still a controversial issue. In the literature, the catalytic results over unpromoted and promoted sulfated zirconia have been discussed in terms of crystalline phase, sulfate content, and acidity [31,32]. First, both aluminum and gallium help the retardation of the phase transformation of $\mathrm{ZrO}_{2}$ from tetragonal to monoclinic. This contributes partly towards the catalytic activities. However, this does not explain the high stability in the promoted catalysis.

In our experiments, if one takes all the above characterization results into consideration, the causes for 
the promotion effect of $\mathrm{Al}$ and $\mathrm{Ga}$ are unexpectedly different. The improvement of activity by $\mathrm{Al}$ in ASZ/MCM-41 is not difficult to understand. In the Al case, DRIFT spectra provide evidence for the promotion of Brønsted acid sites. The high catalytic activity and stability of ASZ/MCM-41 is thus probably mainly caused by the simultaneous presence of Brønsted and Lewis acid sites. On the other hand, acidity characterization of the samples showed no significant difference in nature and strength of the acid sites between SZ/MCM-41 and GSZ/MCM-41 catalysts. TPR profiles, however, indicate that $\mathrm{Ga}$ enhances the sulfate reduction. These results suggest that the nature and strength of the intrinsic acid sites are not sufficient to account for the higher activity of GSZ/MCM-41 catalyst. The reason for the higher activity of the GSZ/MCM-41 is probably related to the higher oxidization ability of $\mathrm{Ga}(\mathrm{III})$ in GSZ/MCM-41 catalyst.

There are two mechanisms for the isomerization of pentane: monomolecular and bimolecular as depicted in Eqs. (1) and (2), respectively [33]. In both, the reaction starts with the formation of carbenium ion on acid sites,

$\mathrm{C}_{5} \mathrm{H}_{12}+\mathrm{H}^{+} \rightarrow \mathrm{C}_{5} \mathrm{H}_{11}^{+} \mathrm{H}_{2}$

and in the monomolecular mechanism, the rearrangement of the pentyl cation into isopentyl action is followed by hydride transfer leading to isopentane.<smiles>CCCCCCCCCCCCCCCCCCCCCCCCCC</smiles>

The bimolecular mechanism requires the equilibrium formation of pentene (Eq. (2)) followed by the reaction between pentene and pentyl cation to form dimeric $\mathrm{C}_{10}{ }^{+}$species.

$\mathrm{C}_{5} \mathrm{H}_{11}^{+} \leftrightarrow \mathrm{C}_{5} \mathrm{H}_{10}+\mathrm{H}^{+}$

The dimeric species can re-arrange and scission to form isopentane. However, it is also known to produce $\mathrm{C}_{3}-\mathrm{C}_{5}$ species and cyclic olefins and thus coking [34]. The fact that we have little decay of catalytic activity and almost single product of isopentane in both Al- and Ga-promoted SZ indicates that only monomolecular mechanism operates in our catalysis reaction. This can be expected in ASZ/MCM41 since its stronger Brønsted acidity shifts the equilibrium in Eq. (2) towards pentyl cation and thus promotes monomolecular reaction (1). $\mathrm{C}_{3}-\mathrm{C}_{5}$ species and coking are then avoided.

For Ga-promoted SZ, the enhanced acidity does not come directly from framework substitution by Ga itself. However, we have seen $\mathrm{Ga}(\mathrm{III})$ can help the uptake of hydrogen to form hydrogen sulfide. It is known that hydrogen can be converted into acid sites [33]. We propose that $\mathrm{Ga}(\mathrm{III})$ indeed helps the formation of acid site by the redox reaction;

$\mathrm{Ga}(\mathrm{III})+\mathrm{H}_{2} \rightarrow \mathrm{Ga}(\mathrm{I})+2 \mathrm{H}^{+}(\mathrm{ad})$

This increased acidity also shifts the equilibrium in Eq. (2) towards pentyl cation and thus to monomolecular mechanism leading to simple isomerization. Although a much higher temperature $\left(500{ }^{\circ} \mathrm{C}\right)$ than the reaction temperature is needed for hydrogen sulfide desorption from SZ, the acidity production in Eq. (3) is probably operating at a much lower temperature.

The promoting and stabilizing effect of $\mathrm{Al}$ and $\mathrm{Ga}$ on sulfated zirconia in pentane isomerization without the use of expensive Pt is technologically very encouraging. We may thus be able to develop a new generation of catalyst for alkane isomerization. In fact, recently we have found GSZ catalyzes excellently and very stably the isomerization of hexane. Almost all the conversions were isomers of hexane. Cracking products of $\mathrm{C}_{1}-\mathrm{C}_{5}$ were negligible [35]. Further studies to understand the detailed reasons for the excellent catalytic behavior in Al- and Ga-promoted sulfated zirconia for alkane isomerization is desirable.

\section{Acknowledgements}

C.L. Chen thanks the financial support by the Science and Technology Department of Jiangsu Province, China (Project BG2002017) and Key Laboratory of Materials-Oriented Chemical Engineering of Jiangsu Province, China. CYM thanks the support of a MOE research Excellency grant.

\section{References}

[1] K. Arata, Adv. Catal. 37 (1990) 165.

[2] K. Tanabe, H. Hattori, T. Yamaguchi, Crit. Rev. Surf. Chem. 1 (1990) 1.

[3] T. Yamaguchi, Appl. Catal. 61 (1990) 1.

[4] A. Corma, Chem. Rev. 95 (1995) 559.

[5] X. Song, A. Sayari, Catal. Rev. Sci. Eng. 38 (1996) 329.

[6] G.D. Yadav, J.J. Nair, Micropor. Mesopor. Mater. 33 (1999) 1.

[7] T. Yamaguchi, Appl. Catal. A: Gen. 222 (2001) 237.

[8] K. Ebitani, H. Konno, T. Tanaka, H. Hattori, J. Catal. 143 (1993) 322.

[9] K. Ebitani, J. Konishi, H. Hattori, J. Catal. 130 (1991) 257.

[10] K. Ebitani, J. Tsuji, H. Hattori, H. Kita, J. Catal. 135 (1992) 609.

[11] M. Hino, K. Arata, J. Chem. Soc. Chem. Commun. (1995) 789.

[12] T. Shishido, H. Hattori, J. Catal. 161 (1996) 194.

[13] X. Song, K.R. Reddy, A. Sayari, J. Catal. 161 (1996) 206.

[14] C.H. Lin, C.Y. Hsu, J. Chem. Soc. Chem. Commun. (1992) 1479.

[15] C.Y. Hsu, V.K. Patel, J.T. Wei, H.K. Myers Jr., US Patent No. 5,019,671 (1991).

[16] E.J. Hollstein, J.T. Wei, C.Y. Hsu, US Patent No. 4,918,041 (1990).

[17] C.Y. Hsu, C.R. Heimbuch, C.T. Armes, B.C. Gates, J. Chem. Soc. Chem. Commun. (1992) 1645.

[18] A.S. Zarkalis, C.Y. Hsu, B.C. Gates, Catal. Lett. 29 (1994) 235.

[19] M. Risch, E.E. Wolf, Catal. Today 62 (2000) 255.

[20] Q.H. Xia, K. Hidajat, S. Kawi, Chem. Commun. (2000) 2229.

[21] Q.H. Xia, K. Hidajat, S. Kawi, J. Catal. 205 (2002) 318.

[22] W.M. Hua, Y.H. Yue, Z. Gao, J. Mol. Catal. A 170 (2001) 195.

[23] H. Matsuhashi, M. Tanaka, H. Nakamura, K. Arata, Appl. Catal. A 208 (2001) 1 .

[24] C.L. Chen, S. Cheng, H.P. Lin, S.T. Wong, C.Y. Mou, Appl. Catal. A 215 (2001) 21.

[25] C.L. Chen, T. Li, S. Cheng, H.P. Lin, C.J. Bhongale, C.Y. Mou, Micropor. Mesopor. Mater. 50 (2001) 201.

[26] W. Wang, C.L. Chen, N.P. Xu, C.Y. Mou, Green Chem. 4 (2002) 257.

[27] H.P. Lin, S. Cheng, C.Y. Mou, Micropor. Mater 10 (1997) 111. 
[28] Y.Y. Huang, B.Y. Zhao, Y.C. Xie, Appl. Catal. A 173 (1998) 27.

[29] F.F. Bentley, L.D. Smithson, A.L. Rozek, Infrared Spectra and Characteristic Frequencies $\sim 700-300 \mathrm{~cm}^{-1}$, Interscience, $104 \mathrm{pp}$.

[30] M.L. Occelli, D.A. Schiraldi, A. Auroux, R.A. Keogh, B.H. Davis, Appl. Catal. A 209 (2001) 165.

[31] Z. Gao, Y.D. Xia, W.M. Hua, C.X. Miao, Topics Catal. 6 (1998) 101.
[32] J.A. Moreno, G. Poncelet, J. Catal. 203 (2001) 453.

[33] Y. Ono, Catal. Today 81 (2003) 3.

[34] N. Essayem, Y. Ben Taârit, C. Feche, P.Y. Gayraud, G. Sapaly, C. Naccache, J. Catal. 219 (2003) 97.

[35] C.J. Cao, S. Han, C.L. Chen, N.P. Xu, C.Y. Mou, Catal. Commun. 4 (2003) 511. 